\title{
Comparative Study on Nutritive Content of Finger Millet-Wheat Composite Bread Fermented With Lactic Acid Bacilli and Yeast
}

\author{
Ramesh Mythrayee ${ }^{1}$, Amritkumar Pavithra ${ }^{1 *}$ \\ ${ }^{1}$ Post graduate and Research Department of Biotechnology, Women's Christian College, College Road, \\ Chennai-600006, India \\ *Corresponding author: Assistant Professor, Post graduate and Research Department of Biotechnology, \\ Women's Christian College, College Road, Chennai-600006, India
}

\begin{abstract}
Different forms of bread enriched with millets (composite breads) are being tried, to improve the nutritive quality of the bread. In the present study, one of the traditional millets of south India, Finger millet (Ragi), was mixed with whole wheat flour and fermented with lactic acid bacteria (LAB) as well as Baker's yeast. The composite breads were evaluated for physical, nutritional and shelf life properties, and compared with the commercially available white bread. The nutritive content of both the types of composite bread were superior to the commercially available white bread, serving as a rich source of calcium (296\%mg as against $40 \% \mathrm{mg}$ in white bread). They also showed better shelf-life due to their lower gluten and moisture content. Finger millet-whole wheat composite bread fermented with Baker's yeast had higher Vitamin B group (1.09\% $\mathrm{mg}$ ) compared to the same fermented using $L A B(0.40 \% \mathrm{mg})$ and the white bread $(0.15 \% \mathrm{mg})$. This study attempted to formulate alternative and healthy bread making without use of chemicals associated with modern bread baking.
\end{abstract}

Keywords: Finger millet, lactic acid bacteria, Vitamin B group, composite bread, whole wheat flour

\section{Introduction}

Bread is a staple food prepared from fermented dough of flour and water by baking. Bread, in all its various forms, is still the most widely consumed food in the world. Not only is an important source of carbohydrates, it is also convenient to consume and compact, which probably explains why it has been an integral part of our diet for thousands of years. It is one of the oldest prepared foods with findings suggesting it to be one of the oldest food technologies practiced by people of Babylon, Egypt, Greece and Rome, 30,000 years ago. [1]. Since then, bread making technology has evolved tremendously over the years, with incorporation of various ingredients and methodologies to improve the taste, texture as well as visual appeal of the modest food of the world. The basic ingredients typically include, white flour, obtained from wheat kernel by extracting the starchy endosperm after removing wheat bran and germ, sugar, fat, salt, water and Baker's yeast, which undergo the basic process of mixing, kneading, fermentation and finally baking to obtain the end product of golden brown crusted spongy, white bread. Baker's yeast (Saccharomyces cerevisiae) is the most common yeast used in bread making. Yeast cells are rich in enzymes that metabolize sugars (glucose, fructose, sucrose and maltose) during fermentation under anaerobic conditions producing carbon dioxide, which expands during baking at high temperatures $\left(150^{\circ} \mathrm{C}-200^{\circ} \mathrm{C}\right)$ leaving fine holes as they leave the bread, which is typically described as leavening of bread. Yeast also aids in gluten network formation and release of certain aromatic compounds, enhancing the flavor. Sugar added helps in fermentation, while the salt added strengthens the gluten in the flour as well as helps yeast in controlled expansion of the dough. Fat added in the form of butter or vegetable oil, aid in shortening of bread providing the texture. Fresh bread usually presents an appealing brownish and crunchy crust, a pleasant aroma, fine slicing characteristics, a soft and elastic crumb texture, and a moist mouth-feel [2].

Sourdough is an intermediate product between dough and traditional bread preparation, containing flour, water and metabolically active microorganisms, mainly lactic acid bacteria (LAB) and yeast [3]. The application of sourdough has a long tradition in the production of wheat and rye breads [4]. Sourdough plays an important role in the development of the sensorial, nutritional, and safety quality of fermented products [5]. During the fermentation of the dough, the metabolic products of LAB improve the physical, rheological and nutritional properties of bread which include increase in shelf life, improvement in texture and palatability, stability and bioavailability of bioactive compounds and enhancement of mineral bioavailability $[6,7,8]$.

White bread is a rich source of carbohydrates, energy, and to some extent proteins, but they do lack important dietary supplements such as fiber, vitamins and minerals and essential amino acids. Bread can be fortified with these essential dietary supplements and is hence considered as a good source of functional foods. With increasing consumer awareness to eat healthy, fortified or functional foods are on the rise [9]. While addition of purified supplements to the white flour is an easy and popular option, considering usage of millet 
flour as fortification is an option less exploited. Millets are a group of small seeded grasses widely cultivated in the semi-arid tropical regions of Asia and Africa. Many types of millet are indigenous to certain places and are favored due to their short growing season under dry, high-temperature conditions combined with high productivity. They are highly nutritious, non-glutinous and nonacid forming foods, making them least allergenic and most easy to digest. Being rich in fiber, millets release lesser percentage of glucose, over a longer period of time, lowering the risk of diabetes. Millets are also rich in minerals like iron, magnesium, phosphorous and potassium. Among them, finger millet (Ragi) is the richest in calcium content, and is also rich in protein, essential amino acids, iron, phosphorus, fiber and certain vitamins such as vitamin A and vitamin B group $[10,11]$.

Bread making has grown into a big industry being completely mechanized for large scale production, and with growing consumer demand for quality, longer shelf-life and volume, food additives such as emulsifiers, antioxidants, acid regulators and preservatives are added to achieve those desired qualities [12]. Addition of emulsifiers is particularly important for industrial bread baking as these impart greater dough strength to withstand machine handling, improves hydration, crumb structure, slicing characteristics, gas holding capacity as well as shelf life [2]. Nearly 60 approved chemicals are used as additives in the making of flour and bread, to improve their quality and shelf life. At any given time, a minimum of eight or more of these additives are commonly used by most of the bread manufacturers. Chlorine dioxide is one such that bleaches the flour snow white and removes strong odors. Chlorine dioxide inactivates vitamin E, and reacts with certain proteins to form methionine sulfoxide, which is known to cause central nervous system damage in humans. Chlorine also forms compounds such as dichlorostearic acid, which remain in the flour. Other bleaching agents such as benzoyl peroxide and nitrogen peroxide are also used along with maturing agents such as potassium bromate, potassium iodate and azocarbonamide. Potassium bromate and potassium iodate create more holes in the dough, making it lighter and also reduce the fermentation time drastically. Recent studies have shown potassium bromate to be associated with cancer and potassium iodate associated with gastrointestinal distress and destruction of red blood cells when administered to test animals. The present study aims to formulate alternative and safe fermentation methods for baking bread using Baker's yeast, LAB, composite flour of whole wheat and finger millet, in a healthy way, without the use of chemical additives which are commonly associated with bread baking, and compare the physical, nutritional and rheological properties with the commercially available white bread.

\section{Materials And Methods}

Locally available wheat grains and finger millet seeds were procured and ground into powder in flourmill. The powders were sieved through $2 \mathrm{~mm}$ mesh $(34 \mathrm{~cm}$ diameter sieve) to obtain the whole wheat flour and finger millet flour, respectively. Two different types of composite bread formulations, fermented using Baker's yeast and lactic acid bacteria, respectively, were used in this study. The formulations developed in this study are shown in Table 1, along with the commercially available bread with common baker's formulation, used as control in this study.

Baking soda and baking powder were added in both the formulations to improve the leavening ability. The control white bread had chemical additives Preservative-282 (Calcium propionate), Acid Regulation-260 (Acetic Acid), Flour treatments Agents-510 (Ammonium Chloride), Antioxidant-300 (Phenolic Antioxidant) and Improver-1100 in small measures.

For the Baker's yeast fermented composite bread, the two flours: whole wheat and finger millet, were mixed in equal proportions (1:1). Dry yeast was dissolved in warm water and stirred well. All ingredients were brought together, mixed and kneaded well and left for fermentation for one hour. The fermented dough was baked at $150^{\circ} \mathrm{C}$ for 30 minutes and then cooled and sliced. Fig. 1 shows various stages of making of Baker's yeast fermented composite bread.

For the LAB fermented composite bread, the two flours: whole wheat and finger millet, were mixed in 2:1 ratio. A commercially available sour curd in $200 \mathrm{ml}$ pack was used as LAB source. All ingredients were brought together, mixed and kneaded well and left for fermentation for one hour. The fermented dough was baked at $150^{\circ} \mathrm{C}$ for 30 minutes and then cooled and sliced. Fig. 2 shows various stages of making of LAB fermented composite bread.

\subsection{Quality evaluation of Finger millet-whole wheat composite bread}

Physical properties of the bread such as colour, texture, and weight were noted.

Biochemical analysis to evaluate the nutritive content was carried out on both the types of composite bread. The tests included estimation of amount of moisture, protein, energy, crude fiber, fat, carbohydrate, calcium, vitamin B group and folic acid, performed in accordance with Indian Standard Bakery products - Methods of analysis IS 12711: 1959 (Reaffirmed 1994), IS/ISO 5983-1:2005, IS 7219, AOAC Official method 928.08 \& 943.01 \& FSSAI Manual, Cereals \& Pulses, 2016. In addition, the shelf-life of the two composite breads were compared 
with the white bread. The results obtained were compared with the data available on commercially available white bread, which was used as control for this study.

\subsection{Physical and Rheological properties}

\section{Results And Discussion}

The loaf weight of composite bread fermented using Baker's yeast weighed $410 \mathrm{~g}$ while the one fermented using lactic acid bacilli (LAB) weighted 430g. The commerically available white bread used as control weighed $400 \mathrm{~g}$. The increase in loaf weight in the composite bread compared to the commercially available white bread could be due to the decrease in gluten content in them in comparison with the control bread made out of only white flour. Gluten is a protein composite which plays a key role in water absorption capacity, cohesiveness, viscosity and elasticity of dough, all of which add up to the quality of the bread. Gluten proteins contain two main components: the soluble gliadins and the insoluble glutenins. Glutenin contributes to the elastic character of gluten while gliadin contributes to extensibility, a balance of both is necessary for superior baking performance. The gluten network formed during mixing and fermentation helps in holding gas produced during fermentation, making the dough to rise and maintain its shape, even after baking [13]. In the present study, the Baker's yeast fermented composite bread had only 50\% whole wheat flour (1:1 ratio), while the LAB fermented one had two thirds of whole wheat flour (2:1 ratio). The decrease in gluten content in the composite flour, especially in the yeast fermented composite bread, has certainly had an impact on the physical and rheological properties of the end product. Both the types of composite bread were brown in colour and the crusts were dark brown in colour. The textures were slightly rough on surface and holes were seen inside, although with reduced porosity. The composite breads were also dense in nature with less elasticity in comparison with the white bread, possibly due to the lower gluten content and higher finger millet content. The results observed in this study were in agreement with the findings by Wang et al., [14] who studied the quality of white bread fermented with LAB and that of Devani et al., [15] who studied the quality of white bread enriched with finger millet flour. The overall rough texture and dense nature can thus be attributed to the decrease in gluten content in the composite bread.

In this study, the shelf-life of the composite breads were also compared with the control white bread, by observing for visible changes on the surface for 10 days, in their packed condition. The control bread showed growth of green moulds on day four and by day 10 (Fig.3), black mouldy growth covered most areas of the bread within the packing. On lactophenol cotton blue staining (Fig.4), the fungi were identified as Aspergillus niger and Penicillium spp. In both the types of composite bread, there were no visible growth observed on the surface upto day 10. The composite breads appeared drier than they were on day 1 .

In a study by Corsetti \& Settani., [16] on the role of LAB in white bread, they attributed increased shelf-life of bakery products to the lactic and acetic acids produced by LAB during sourdough fermentation, contributing to decrease in $\mathrm{pH}$ and thus inhibiting the mold growth. In our study, LAB fermented and Baker's yeast fermented composite breads showed similar extended shelf life, which perhaps could be attributed to the lower gluten content and dense texture. Primo-Martín et al., [17] have observed that during storage, the crispness of bread crust alters as a result of changes in moisture content resulting from redistribution of moisture within the bread as well as between the bread and its environment. Moisture content is also affected by the flour protein content and by selectively modifying the crust protein phase of a model bread with enzymes, as well as by storing breads at high and low relative humidity, ranging from 80-40\% Relative Humidity [17].

\subsection{Nutritional properties}

The results of the nutritional parameters of the two types of composite breads in comparison with the control white bread are shown in Table 2. The nutrtitive content of both the composite breads were comparitively higher than the control white bread. The lower moisture content correlates with the physical properties observed and the extended shelf-life finding. Both the composite breads were comparable in the nutritive parameters tested, except for the vitamin B group content, which was higher in the Baker's yeast fermented bread than LAB fermented bread. But the overall levels of vitamin B group in both the breads were higher than the control white bread. This vitamin complex is exclusively found in the wheat bran and kernel, which are discarded during processing to make the white flour. As our composite bread formulation had whole wheat flour, we could retain the benefit of this vitamin complex in our breads. Copping and Roscoe [18], through an exhaustive study have demonstrated that yeast contributes to the vitamin B complex proportion in the bread. Our findings of higher levels of vitamin B group in Baker's yeast fermented bread than the LAB fermented one, correlates with their findings. Finger millet, being rich in calcium as well as in protein, essential amino acids, iron, phosphorus, fiber and certain vitamins such as vitamin A and vitamin B group, has significantly contributed to the nutritive content in our composite breads formulated in this study. The findings in this study is also similar to that observed by Devani et al., [15] and Desai et al. [11], who used finger millet fortified white flour for bread making. The most important significance of our formulation is that it has been made without the use of commonly used chemical additives and we have replaced the commonly used white 
sugar with palm candy. Palm candy is made from the sweet sap collected from the inflorescence of Palmyra Palm tree, which is then heated and crystallized to sugar. It has a number of minerals, vitamins, calcium, iron\& phytonutrients including zinc and potassium. It has low Glycemic Index. It serves as a good source of Vitamin B1, B2, B3, B6 and B12. (http://www.medindia.net/patients/lifestyleandwellness/health-benefits-of-palmsugar.htm). More importantly, it is an unbleached sweetener, coming without the burden of sulphur compounds that normally comes with the refined table sugar.

\section{Conclusion}

Two types of composite bread comprising of Finger millet (Ragi) flour and whole wheat flour, fermented using Baker's yeast and Lactic acid bacilli (LAB) were formulated in this study and compared with the commercially available white bread. The study demonstrated the superior nutritive content of both the types of composite bread in comparison with the control white bread. Finger millet-whole wheat composite bread fermented with Baker's yeast had higher moisture content (21.24\%) and Vitamin B group (1.09\% $\mathrm{mg}$ ) compared to the same fermented using LAB. In addition, the composite bread showed better shelf-life than the control bread, which is attributed to the lower gluten and moisture content. By formulating composite bread with the locally grown millets, whole wheat flour and unrefined palm candy, and doing away with the chemical additives, we have taken baby steps towards providing a healthy and nutritive option for the ubiquitous white bread.

\section{Acknowledgement}

The authors are thankful to the Management of Women's Christian College, Chennai, for providing the infrastructure to conduct this research work.

\section{Funding}

This research did not receive any specific grant from funding agencies in the public, commercial, or not-forprofit sectors.

\section{Reference}

[1] Matz, S. A. The chemistry and technology of cereals as food and feed (AVI Books pp. 1-2; 1995).

[2] Giannou, V., Kessoglou, V., Tzia, C. Quality and safety characteristics of bread made from frozen dough. Trends in Food Science and Technology, 14 (3), 2003, 99-108.

[3] Rollán G, Gerez CL, Dallagnol AM, Torino MI, Font G Update in bread fermentation by lactic acid bacteria. Méndez-Vilas A (ed) Current Research, Technology and Education Topics in Applied Microbiology and Biotechnology, 1st edn. Fomatex, Spain, 2010, 1168-1174.

[4] Salovaara H. Lactic acid bacteria in cereal-based products. Salminen S, von Wright A, ed. Lactic acid bacteria- Microbiology and functional aspects. (New York, NY: Marcel Dekker, 115-137, 1988).

[5] Hammes WP, Gänzle MG. Sourdough breads and related products. Woods BJB, ed. Microbiology of Fermented Foods Vol. 1. (London: Blackie Academic/Professional, 199-216, 1998)

[6] De Angelis M, Gallo G, Corbo MR, McSweeney PLH, Faccia M, Giovine M, Gobbetti M. Phytase activity in sourdough lactic acid bacteria: Purification and characterization of a phytase from Lactobacillus sanfranciscensis CB1. International Journal of Food Microbiology, 87, 2003, 259-270.

[7] Gobbetti M, Rizzello JC, Di Cagno R, De Angelis M. Sourdough lactobacilli and celiac disease. Food Microbiology, 24, 2007, 187196.

[8] Rollán G, De Angelis M, Gobbetti M, Font de Valdez G. Proteolytic activity and reduction of gliadin-like fractions by sourdough lactobacilli. Journal of Applied Microbiology, 99, 2005, 1495-1502.

[9] Ndife, J. Okaka, J.C., Functional Foods: Prospects and challenges in Nigeria. J. Sci. Technol. 1(5), 2009, 1-6.

[10] Gopalan C, Ramasastri BV \& Balasubramanian SC. Nutritive value of Indian foods. (NIN, ICMR, Hyderabad, 59-67, 2004).

[11] Desai AD, Kulkarni SS, Sahu AK, Ranveer RC \& Dandge PB,. Effect of supplementation of malted ragi flour on the nutritional and sensorial quality characteristics of cake. Advanced Journal of food Science and Technology, 2(1), 2010, 67-71.

[12] Stampfli, L., Nersten, B. Emulsifiers in bread making. Food Chemistry 52 (4), 1995, 353-360.

[13] Wieser H. Chemistry of gluten proteins. Food Microbiology, 24(2), 2007, 115-119

[14] Wang H , Hwang C, Tzeng Y-M , Hwang W-Z and Mau J-L. Quality of white bread made from lactic acid bacteria-enriched dough. Journal of Food Processing and Preservation, 36, 2012, 553-559

[15] Devani BM, Jani BL, Kapopara MB, Vyas DM and Mingthoujam MD. Study on quality of white bread enriched with finger millet flour. International Journal of Agriculture, Environment and Biotechnology, 9(5), 2016, 903-907

[16] Corsetti A, Settani L. Lactobacilli in sourdough fermentation. Food Research International, 40, 2007, 539-558.

[17] Primo-Martín C, van de Pijpekamp A, van Vliet T, de Jongh HHJ, Plijter JJ, Hamer RJ. The role of the gluten network in the crispness of bread crust. Journal of Cereal Science, 43(3), 2006, 342-352

[18] Copping, A. M. \& Roscoe, M. H. The water-soluble B-vitamins in yeast, flour and bread. Biochem. J., 31(10), 1937, 1879-1902 


\section{Figures and Tables}

Fig.1: Different stages of making of finger millet-whole wheat bread, fermented using Baker's yeast
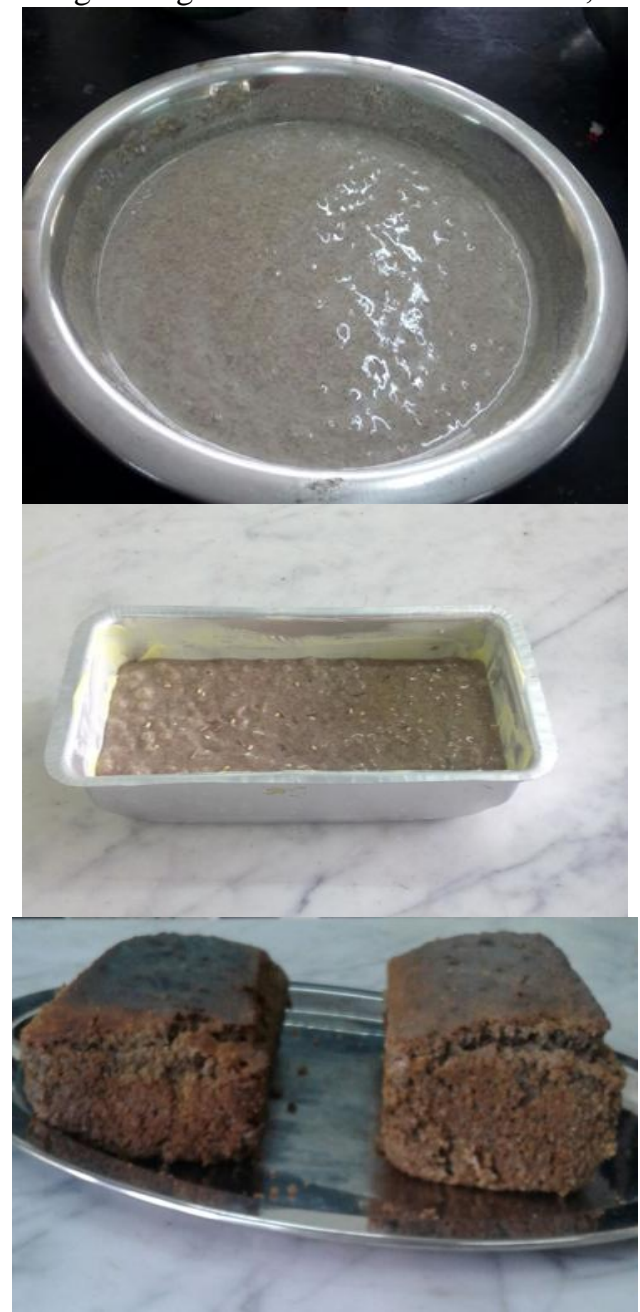

Fig.2: Different stages of making of finger millet-whole wheat bread, fermented using LAB

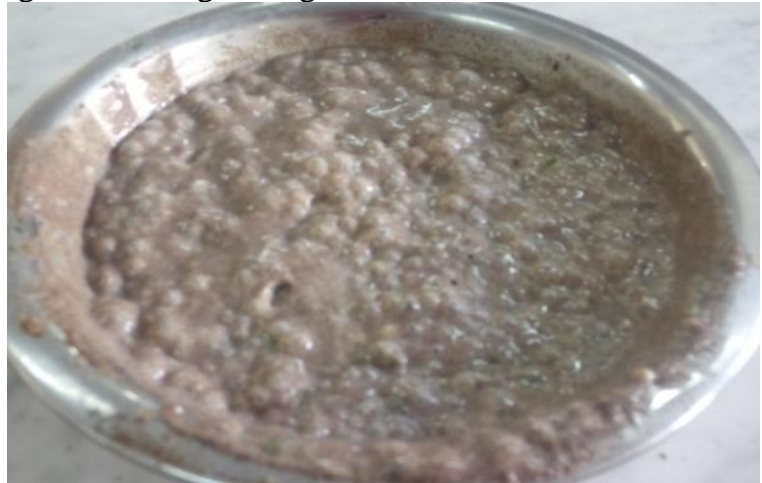




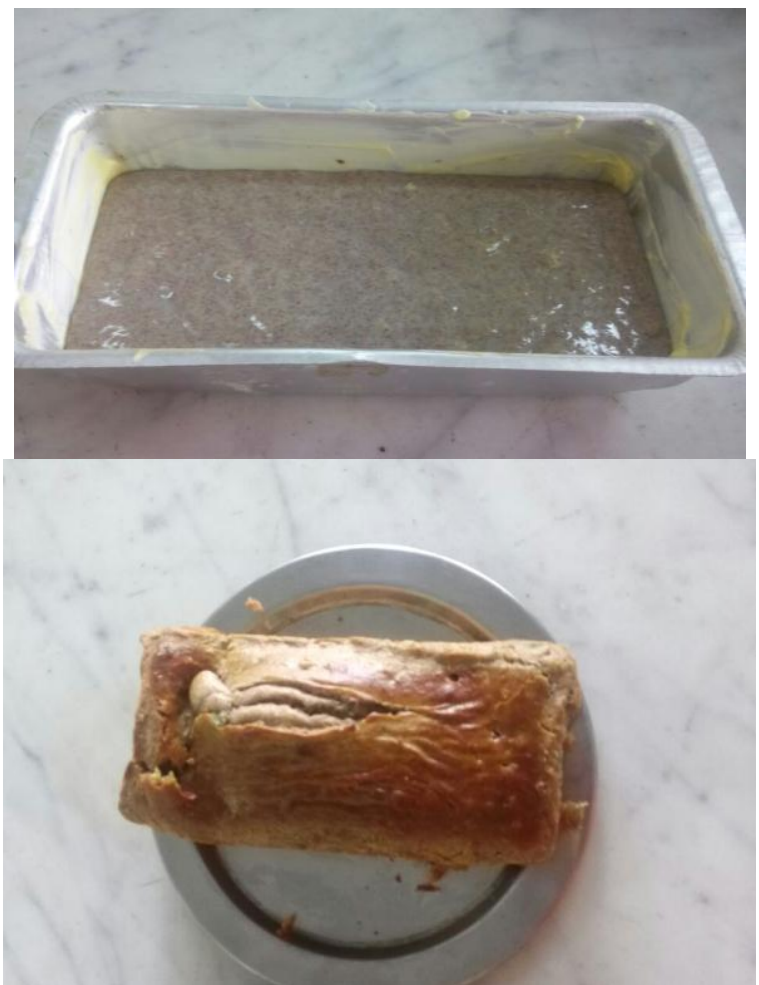

Fig.3: Shelf-life after 10 days. (a) showing no visible changes on composite breads (b) showing black moldy growth on surface on control white bread.

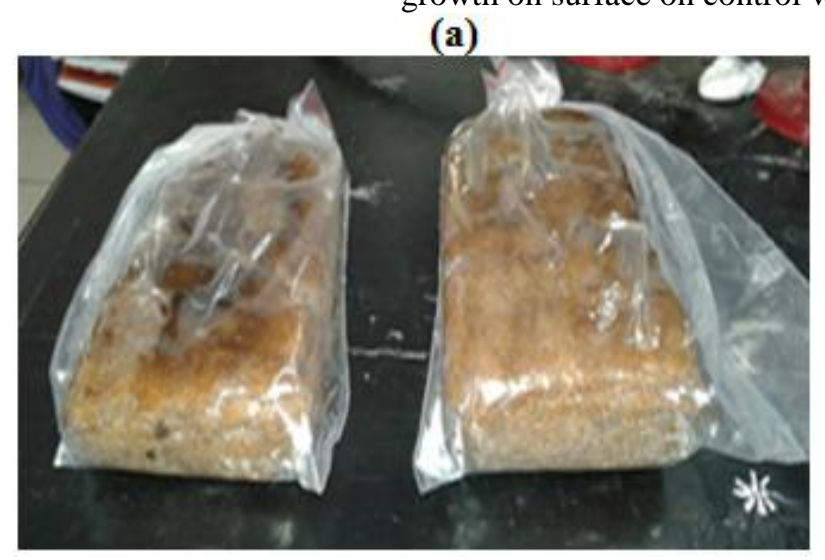

(b)

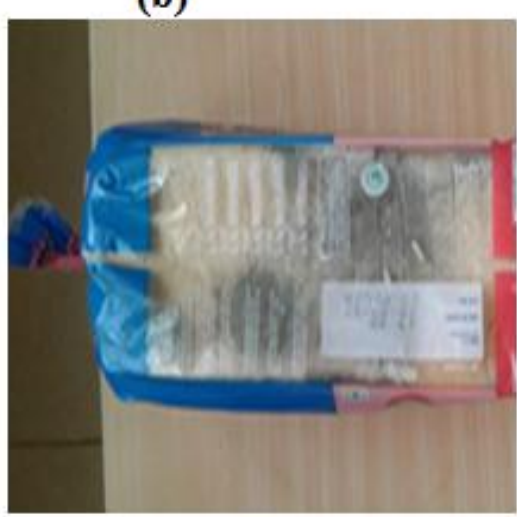

Fig.4: Fungi identified by Lactophenol cotton blue staining method.

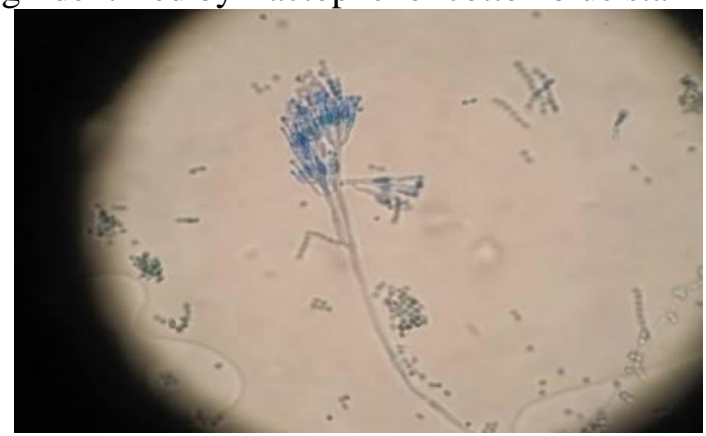

(a) Aspergillus niger

(b) Penicillium spp. 


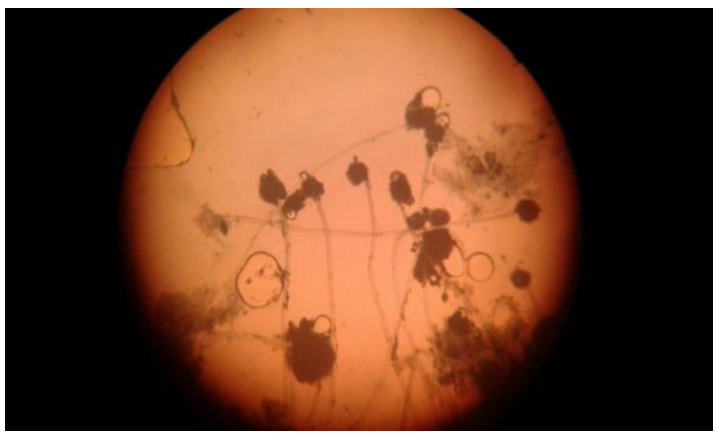

Table 1: Formulation of two types of composite bread developed in this study in comparison with the Baker's formulation of white bread

\begin{tabular}{|l|l|l|l|}
\hline $\begin{array}{l}\text { Ingredients } \\
(\mathrm{g})\end{array}$ & $\begin{array}{l}\text { Composite bread } \\
\text { fermented with Baker's } \\
\text { yeast }\end{array}$ & $\begin{array}{l}\text { Composite bread fermented with } \\
\text { Lactic acid bacteria (LAB) }\end{array}$ & $\begin{array}{l}\text { White bread with Baker's } \\
\text { formulation }\end{array}$ \\
\hline White flour $(\mathrm{g})$ & - & - & 200 \\
\hline Finger millet flour $(\mathrm{g})$ & 60 & 60 & - \\
\hline Whole wheat flour $(\mathrm{g})$ & 60 & 120 & - \\
\hline Skimmed milk powder $(\mathrm{g})$ & 30 & 30 & 34 \\
\hline Baker's yeast $(\mathrm{g})$ & 6 & - & 6 \\
\hline Sour curd $(\mathrm{ml})$ & - & 200 & - \\
\hline Palm candy(g) & 30 & 30 & - \\
\hline Sugar $(\mathrm{g})$ & - & - & 36 \\
\hline Salt $(\mathrm{g})$ & & & 4 \\
\hline Baking soda(g) & 2 & 2 & \\
\hline Baking powder(g) & 2 & 2 & \\
\hline Vegetable oil $(\mathrm{ml})$ & 10 & 10 & 15 \\
\hline Water $(\mathrm{ml})$ & 250 & - & 150 \\
\hline TOTAL & 450 & 454 & 411 \\
\hline
\end{tabular}

Table 2: Nutritive properties of the two composite breads in comparison with the control white bread

\begin{tabular}{|l|l|l|l|l|}
\hline $\begin{array}{l}\text { S. } \\
\text { No. }\end{array}$ & PARAMETERS & $\begin{array}{l}\text { Composite } \\
\text { fermented with Baker's } \\
\text { yeast }\end{array}$ & $\begin{array}{l}\text { Composite bread fermented with } \\
\text { Lactic acid bacteria (LAB) }\end{array}$ & $\begin{array}{l}\text { White bread with } \\
\text { Baker's formulation }\end{array}$ \\
\hline 1. & Moisture Content (\%) & 21.24 & 18.24 & 37.5 \\
\hline 2. & Fat (\%) & 1.82 & 1.86 & 2 \\
\hline 3. & Crude Fibre (\%) & 2.74 & 2.90 & 0.20 \\
\hline 4. & Calcium (\%mg) & 296 & 272 & 40 \\
\hline 5. & Protein (\%) & 6.79 & 6.96 & 7.30 \\
\hline 6. & Carbohydrate (\%) & 68.92 & 78.90 & 51 \\
\hline 7. & Energy (Kcal/g) & 351 & 362 & 216 \\
\hline 8. & Vitamin B Group (\%mg) & 1.09 & 0.40 & 0.15 \\
\hline 9. & Folic Acid (\%mg) & 0.17 & 0.19 & 0.11 \\
\hline
\end{tabular}

